DE

M E D I C I N A

T R O P I C A L

$\mathrm{DE}$

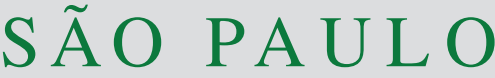

JOURNAL OF THE SÃO PAULO INSTITUTE OF TROPICAL MEDICINE

${ }^{1}$ Universidade Federal do Triângulo Mineiro, Departamento de Clínica Cirúrgica,

Uberaba, Minas Gerais, Brazil

2Universidade Federal do Triângulo Mineiro, Departamento de Clínica Médica, Uberaba, Minas Gerais, Brazil

Correspondence to: Adilha Misson Rua Micheletti

Universidade Federal do Triângulo Mineiro, Departamento de Clínica Cirúrgica, Rua Getúlio Guaritá, 130, CEP 38025-440, Uberaba, MG, Brazil

Tel: +55 34 3318-5152

E-mail: adilharua@yahoo.com.br

Received: 20 May 2019

Accepted: 9 September 2019

\section{Clinical and anatomopathological aspects of patients with hantavirus cardiopulmonary syndrome in Uberaba, Minas Gerais, Brazil}

\author{
João Paulo Vieira dos Santos' ${ }^{1}$, Sheila Jorge Adad', Mário-León Silva \\ Vergara $^{2}$, Adilha Misson Rua Micheletti ${ }^{(1}$
}

\section{ABSTRACT}

The hantavirus cardiopulmonary syndrome is considered an emerging disease in the Americas. Since 1993, thousands of cases have been reported from different countries, but mainly from Brazil. This study aims to describe some epidemiological, clinical and anatomopathological aspects of patients with hantavirus who presented poor outcome and were autopsied in a teaching hospital in Brazil, from 2000 to 2014. Of the 10 patients included, nine were male (mean age 43.5 years) and seven reported previous contact with rodents. Fever was present in eight of ten patients, dyspnea in nine of ten and myalgia in seven of ten patients; hemoconcentration, leukocytosis, thrombocytopenia and renal involvement were evidenced in all the 10 cases. At autopsy, the main alterations were seen in the lungs: pleural effusion (8/10 cases), increased weight 2.5 to 3 times, congestion/ edema (10/10), interstitial mononuclear inflammation (10/10), alveolar hemorrhage (7/10), pulmonary collapse (7/10), hyaline membranes (7/10) and alveolar neutrophilic infiltrate (2/10). Pericardial effusion (2/10), mild myocardium inflammation (4/10), right ventricle dilation (1/10), polyploidy nuclei (3/10) and pericardial diffuse petechial (1/10) were also observed. The other organs exhibited discrete and non-specific alterations. Currently, this syndrome continues to be associated with high mortality directly linked to a late diagnosis and/or a misdiagnosis in the medical centers where these patients were seen for the first time. The anatomopathological findings at autopsy revealed the final phase of the process with pulmonary alterations, allowing a direct correlation with the severity of respiratory distress observed in these patients at admission.

KEYWORDS: Hantavirus infections. Autopsy. Hantavirus pulmonary syndrome. Hantavirus.

\section{INTRODUCTION}

Hantavirus is a tri-segmented and enveloped RNA virus belonging to Hantaviridae family and Orthohantavirus genus ${ }^{1}$. The virus is kept in the wild by chronic rodent infection, and human infection occurs by direct contact with contaminated animal excreta (saliva, feces, and urine) or by aerosols ${ }^{2,3}$. The first case of hantavirus cardiopulmonary syndrome (HCPS) was reported in North America in 1993; in the same year a similar case occurred in Juquitiba city, Sao Paulo State, Brazil. The isolated virus in this case was renamed with the city's name ${ }^{4}$. Since then, several thousand cases have been reported in a number of Brazilian States and other countries. Different viruses have been associated with HCPS, such as Araraquara, Castelo dos Sonhos, Anajatuba, Laguna Negra and Rio Mamore ${ }^{5,6}$.

From 1993 to 2018, 2,117 cases of HCPS were reported from 15 Brazilian 
federal units, mainly in the South region (33.7\%) followed by the Midwest region (25.7\%) and Southeast region $(24.2 \%)$. Most cases acquired the infection in a rural or wild environment, and half of them were involved with occupational activities related to agriculture. The lethality rate observed was $46.5 \%$ to 50\%; in Sao Paulo State recent data pointed to $62.1 \%$ of lethality ${ }^{7-11}$. HCPS comprises four clinical phases: prodromal, pulmonary edema and shock, diuresis and convalescence. The prodromal phase is characterized by non-specific symptoms, such as fever, myalgia, nausea, vomiting, diarrhea, dry cough and headache. After 3 to 6 days, the patient presents abrupt pulmonary edema, respiratory distress and shock. Those who survive evolve with diuresis and subsequently enter the convalescence period ${ }^{12}$.

Several authors have suggested that the viral replication associated with hematological alterations and the host immune responses of specific tissue proinflammatory type constitute the most important pathophysiological mechanism in HCPS $^{12}$. Chronologically, this fact coincides with the evolution to severe respiratory failure due to endothelial lesion, leading to the increment of capillary permeability that ultimately explains the injuries seen in the final phase $\mathrm{e}^{13}$.

According to the literature review, there are few studies focused on the autopsy findings of patients with HCPS. For emerging diseases, these studies become extremely relevant and can contribute to improve the quality of clinical diagnosis and patients' management, and to the better understanding of pathophysiologic aspects ${ }^{1,2,14}$. Since the first report of HCPS, sporadic cases have been seen every year in the Triangulo Mineiro Southeast region of Brazil $^{15-17}$. The present study aims to present some clinical and autopsy findings of patients with HCPS from a teaching hospital in Brazil.

\section{MATERIALS AND METHODS}

This descriptive and retrospective morphological study reports 10 patients with HCPS who died a few hours or days after admission, and who underwent autopsy from 2000 to 2014 at the Special Pathology Unit, Clinical Hospital of the Triangulo Mineiro Federal University, Uberaba, Brazil. The diagnosis of hantavirus infection was ascertained by enzyme-linked immunosorbent assay (ELISA) to hantavirus specific IgM antibody In eight cases, and by immunohistochemistry (Hantavirus NC Antibody HN-1, Santa Cruz Biotechnology) in the other two cases by the analysis of lung, liver, or renal tissue fragments. The most relevant epidemiological, clinical and laboratory data of these cases were recorded through a review of the patients' medical records and autopsy reports.
The study was approved by the Research Ethics Committee of the University under the protocol $\mathrm{N}^{\circ} 1170$.

\section{RESULTS}

From 2000 to 2014, 867 autopsies were performed, of which $17(1.9 \%)$ had a presumptive HCPS diagnosis, and ten had diagnostic confirmation by ELISA or immunohistochemistry methods. From these, nine cases were male (median age 43.5 years). Most of these cases occurred during the winter season in the Triangulo Mineiro region, and previous contact with rodents had been reported in seven cases. Fever, dyspnea and myalgia were the most common reported symptoms; and hemoconcentration, leukocytosis, thrombocytopenia and renal involvement were observed in all the 10 cases. Nine patients were severely ill with respiratory distress when they were admitted at the tertiary hospital and four of them presented shock. Death occurred due to respiratory failure in all the 10 cases. The time elapse between hospitalization and death ranged from 3 hours to 5 days (Table 1 ).

The results of the autopsies revealed that the body mass index ranged from 17.8 to $28.9 \mathrm{~kg} / \mathrm{m}^{2}$ (mean $\left.=25.6 \mathrm{~kg} / \mathrm{m}^{2}\right)$. The mean weight of the hearts was $357.8 \mathrm{~g}$ [eRR $250-350 \mathrm{~g}$ ], and in two cases pericardial effusion was evidenced. Discrete mononuclear inflammatory infiltrate was seen in four cases, discrete dilatation of right ventricle in one case, nuclear polyploidy of the myocardial cells was seen in three cases and diffuse petechial in pericardium was evidenced in one case. Pleural effusion ranged from 120 to $1,680 \mathrm{~mL}$ in the eight cases in which this measurement was possible. The lungs weighed approximately 2.5 to 3 times the normal value $($ mean $=794.5 \mathrm{~g})$ [eRR 275-400 g]. In the microscopic examination, congestion/edema was intense in five cases, moderate in two and discrete in three cases. Pulmonary hemorrhage was present in seven patients (discrete in three, moderate in three and intense in one case). Collapse was evident in seven cases, mainly at the bases of the lungs and associated with massive pleural effusion. In seven cases, hyaline membranes were revealed, focal in four and diffuse in three patients. All cases showed alveolar septa thickening with inflammatory infiltrate predominantly composed of lymphocytes (discrete in eight and moderate in two cases). Alveolar neutrophilic infiltrate was seen in two cases, probably associated with secondary bacterial infection. Table 2 summarizes the weight of the lungs and hearts of the 10 patients necropsied with hantavirus.

The average brain weight was $1440 \mathrm{~g}$ [eRR 1100-1400 g] and there were signs of edema in nine cases. Evidence of bleeding in the cerebellum and cerebral parenchyma was seen in one case. Half of the cases presented hepatomegaly 
Table 1 - Main epidemiological and clinical data of 10 patients with hantavirus cardiopulmonary syndrome presenting poor outcome.

\begin{tabular}{lccccccc}
\hline Case & $\begin{array}{c}\text { Age } \\
\text { (years) }\end{array}$ & Gender & $\begin{array}{c}\text { Occupation/ } \\
\text { profession }\end{array}$ & $\begin{array}{c}\text { Previous contact } \\
\text { with rodents }\end{array}$ & $\begin{array}{c}\text { Onset of } \\
\text { symptoms days }\end{array}$ & $\begin{array}{c}\text { Time of hospital } \\
\text { stay (days) }\end{array}$ & $\begin{array}{c}\text { Severity of clinical } \\
\text { status at admission }\end{array}$ \\
\hline 1 & 45 & M & Engineer & + & 4 & 2 & Mild \\
2 & 58 & M & Seller & NR & 7 & 3 & Severe \\
3 & 44 & M & Bricklayer & + & 2 & $<1$ & Shock \\
4 & 44 & M & Driver & + & 7 & 1 & Severe \\
5 & 14 & M & Student & NR & 4 & $<1$ & Shock \\
6 & 36 & M & Driver & + & 4 & 1 & Shock \\
7 & 47 & M & Driver & + & 1 & $<1$ & Moderate \\
8 & 29 & M & Farmer & NR & 3 & 5 & Severe \\
9 & 43 & M & Farmer & + & 4 & $<1$ & Shock \\
10 & 43 & F & Farmer & + & 5 & 2 & Severe \\
\hline
\end{tabular}

$\mathrm{NR}=$ not reported; + = positive.

Table 2 - Weight of lungs and hearts in 10 necropsied patients with Hantavirus infections at the Clinical Hospital of UFTM.

\begin{tabular}{lccc}
\hline Case & $\begin{array}{c}\text { Right lung } \\
\text { weight }\end{array}$ & $\begin{array}{c}\text { Left lung } \\
\text { weight }\end{array}$ & $\begin{array}{c}\text { Heart } \\
\text { weight }\end{array}$ \\
\hline 1 & $1,105 \mathrm{~g}$ & $950 \mathrm{~g}$ & $440 \mathrm{~g}$ \\
2 & $1,010 \mathrm{~g}$ & $930 \mathrm{~g}$ & $350 \mathrm{~g}$ \\
3 & $\mathrm{NR}$ & $845 \mathrm{~g}$ & $365 \mathrm{~g}$ \\
4 & $1,100 \mathrm{~g}$ & $1,250 \mathrm{~g}$ & $375 \mathrm{~g}$ \\
5 & $600 \mathrm{~g}$ & $500 \mathrm{~g}$ & $245 \mathrm{~g}$ \\
6 & $970 \mathrm{~g}$ & $980 \mathrm{~g}$ & $353 \mathrm{~g}$ \\
7 & $592 \mathrm{~g}$ & $580 \mathrm{~g}$ & $525 \mathrm{~g}$ \\
8 & $580 \mathrm{~g}$ & $680 \mathrm{~g}$ & $354 \mathrm{~g}$ \\
9 & $662 \mathrm{~g}$ & $622 \mathrm{~g}$ & $276 \mathrm{~g}$ \\
10 & $640 \mathrm{~g}$ & $500 \mathrm{~g}$ & $295 \mathrm{~g}$ \\
\hline
\end{tabular}

NR: non-registered.

with a mean weight of $1725 \mathrm{~g}$ [eRR 1200-1600 g]; hepatic steatosis was observed in five cases, severe congestion in four, periportal lymphocytic infiltrate in four, and cholestasis in two. In eight cases there was splenomegaly with an average weight of $251 \mathrm{~g}$ [eRR 100-150 g]; there was red pulp hyperplasia in nineand immunoblastic-type cells in three cases. Even though the macroscopic aspect of the kidneys was normal, eight cases had congestion and two presented evidence of acute tubular necrosis. The bone marrow examination showed delayed maturation of one or more of the cell lines. Figure 1 shows the main findings of autopsy of the HCPS cases herein described.

\section{DISCUSSION}

The epidemiological and clinical profiles of the 10 cases of HCPS herein evaluated are similar to those described in other regions of the country and in the American continent. There was a predominance of males in economically productive age with activities related to the rural area. Regardless of occupation, environmental changes caused by human activity represents the main predisposing risk factor described in epidemiological surveys. Previous contact with rodents is a fact observed in most cases, which is in accordance with data already described ${ }^{7}$. The chronological evolution of clinical symptoms until the onset of dyspnea occurs in a similar way in most cases, and the fast progression of disease led patients to ask for medical care $^{15}$. Due to the seasonality and eventual occurrence of hantaviruses, other more common clinical diagnoses with similar symptoms, such as sepsis, leptospirosis, dengue fever and Influenza often emerge in the differential diagnosis $^{6,18}$.

The first laboratory evaluation of these patients may raise the hypothesis of HCPS. Hemoconcentration, left shift leukocytosis and thrombocytopenia were present in all individuals, which has been observed in other reported case series ${ }^{4,6,15}$. These findings, together with severe hypoxemia and bilateral and homogeneous pulmonary congestion on the chest X-ray-should alert the clinicians to the diagnosis of HCPS. These patients are initially managed as if they have had sepsis and a vigorous fluid infusion is performed, sometimes worsening the pulmonary congestion, contributing to the poor outcome observed in many cases ${ }^{15}$.

The most relevant necropsy findings herein described are predominantly restricted to the lungs. They appeared congestive, edematous, collapsed and with marked increased weight, aside from the presence of pleural effusion in most cases. Microscopic examination revealed edema, hemorrhage, hyaline membranes and mild 

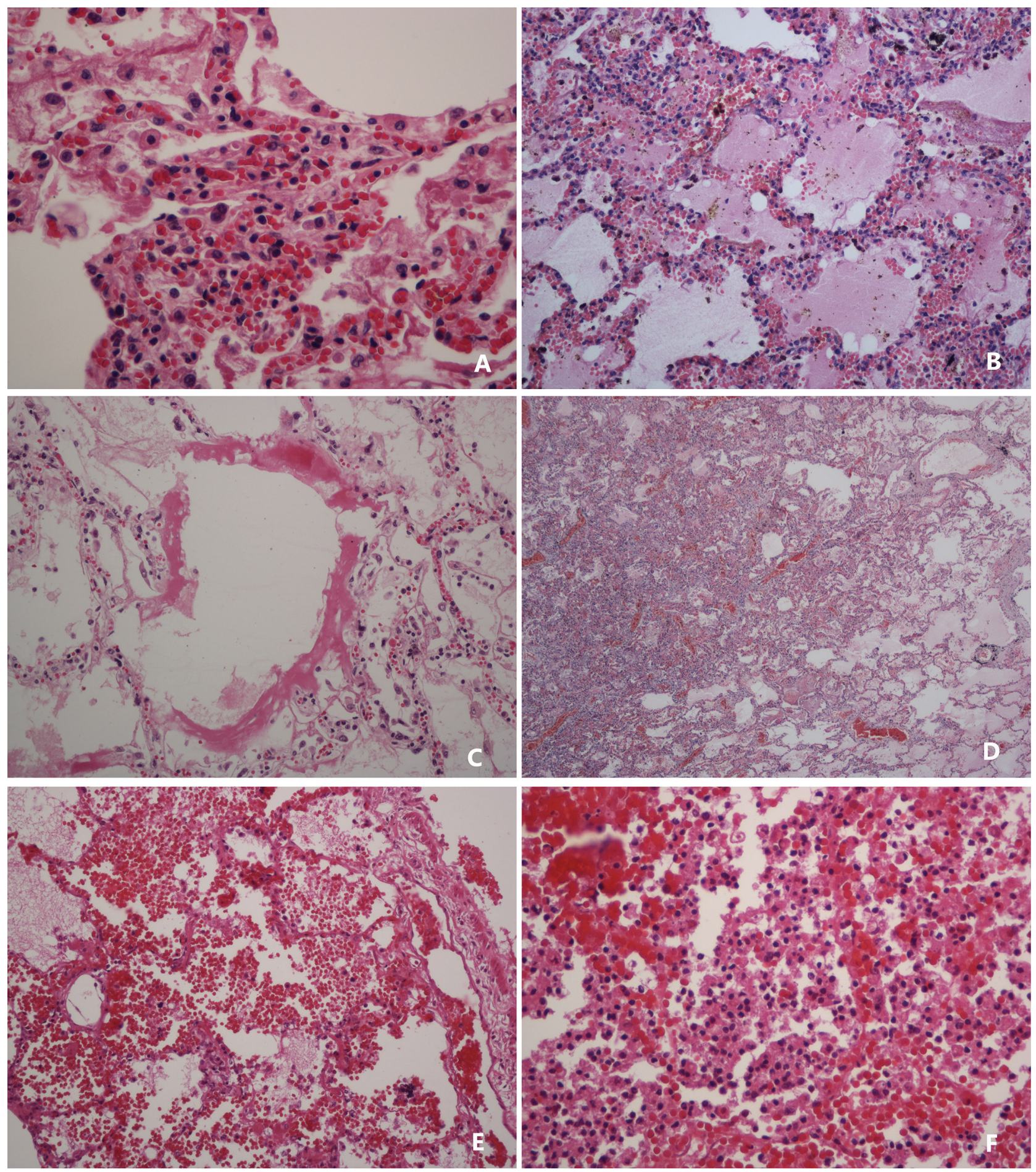

Figure 1 - Photomicrographs of the lungs showing the main pulmonary alterations in patients with HCPS: A) mild inflammatory mononuclear infiltrate in the alveolar septa (HE, $400 \mathrm{x})$; B) intra-alveolar edema (HE, $200 \mathrm{x})$; C) hyaline membrane lining the alveolar wall (HE, $200 \mathrm{x})$; D) collapse focus in the left (HE, $40 \mathrm{x})$; E) intra-alveolar hemorrhage (HE, $200 \mathrm{x})$; F) hemorrhage and neutrophilic inflammatory infiltrate (HE, $400 \mathrm{x})$.

interstitial mononuclear inflammatory infiltrate, with intact alveolar wall type I pneumocytes and no activation of type II pneumocytes. In animal models, a chest plain obtained during the cardiopulmonary phase (some hours before euthanasia) showed severe interstitial infiltrate suggestive of pulmonary edema, besides pleural effusion, as well as cardiomegaly, particularly at the expense of the right ventricle ${ }^{13}$. In addition, the lungs exhibited diffuse and coalescing areas of hyperemia, edema, fibrin, macrophages and scarce neutrophils ${ }^{13}$. Similar findings with 
marked alveolar and interstitial pulmonary edema, minimal epithelial injury and mononuclear interstitial infiltrate were observed in most cases and have been presented and previously described in a case series of autopsies from Chile $^{14}$.

In a study carried out from 1999 to 2002, the hearts of 14 individuals who died during the acute phase of HCPS were compared with others who died due to acute pancreatitis with lung injury or chest trauma. Those who presented HCPS had mild biventricular dilation, inflammatory process with mild to moderate interstitial edema, congestion and mononuclear cell infiltrates. Diffuse reduction of myocytes, coagulative necrosis, basophilic cytoplasm appearance and pyknosis were also found ${ }^{19}$. In contrast, the cases in the present study showed few heart alterations, limited to pericardial effusion in two cases, right ventricular dilation in one case and mild myocardial chronic inflammation in four cases.

Despite the minimal features observed in several organs, this is consistent with the systemic involvement of HPCS, which is supported by studies that detected the presence of viral RNA by reverse transcription polymerase chain reaction in several tissues, and also by hybridization techniques on endothelial cells of the lungs, liver, spleen, kidneys and heart ${ }^{1,13,19}$. In vitro experimental models suggested that the endothelial damage is directly related to the viral cytopathic effect leading to endothelial dysfunction and capillary vasodilation. However, the intrinsic physiopathogenic mechanism of this lesion remains unclear ${ }^{13,20}$.

The autopsy practice is still an important tool in teaching hospitals, allowing the clarification of a diagnosis and a clinical pathological correlation that ultimately assesses the accuracy of the clinical diagnosis. Paradoxically, in recent years, the evidence indicates a substantial decrease in this practice and/or its replacement by modern image-based methodologies, which are not yet available for this purpose in most resource-contraint places.

The anatomopathological features seen at the autopsy of cases with HCPS reveal the final phase of the process with structural pulmonary alterations, allowing a direct correlation with the severity of the respiratory distress observed at admission.

\section{ACKNOWLEDGMENTS}

To the medical colleagues of the Surgical Pathology Unit for the necropsies, to the Clinical Pathology Service for the performance of the serological tests and to the Adolfo Lutz Institute for the performance of immunohistochemistry tests.

\section{AUTHORS' CONTRIBUTIONS}

JPVS: review of cases and preparation of the text; SJA: accomplishment of autopsies and review of the text; MLSV: review of clinical data and the manuscript text; AMRM: accomplishment of autopsies, review of cases and preparation of the text.

\section{REFERENCES}

1. Zaki SR, Greer PW, Coffield LM, Goldsmith CS, Nolte KB, Foucar K, et al. Hantavirus pulmonary syndrome: pathogenesis of an emerging infectious disease. Am J Pathol. 1995;146:55279.

2. Duchin JS, Koster FT, Peters CJ, Simpson GL, Tempest B, Zaki SR, et al. Hantavirus pulmonary syndrome: a clinical description of 17 patients with a newly recognized disease. $\mathrm{N}$ Engl J Med. 1994;330:949-55.

3. Terajima M, Hendershort JD $3^{\text {rd }}$, Kariwa H, Koster FT, Hjelle B, Goade D, et al. High levels of viremia in patients with the hantavirus pulmonary syndrome. J Infect Dis. 1999;180:20304.

4. Silva MV, Vasconcelos MJ, Hidalgo NT, Veiga AP, Canzian M, Marotto PC, et al. Hantavirus pulmonary syndrome: report of the first three cases in São Paulo, Brazil. Rev Inst Med Trop Sao Paulo. 1997;39:231-4.

5. Guterres A, Oliveira RC, Fernandes J, Schrago CG, Lemos ER. Detection of different South American hantaviruses. Virus Res. 2015;210:106-13.

6. Ferreira MS, Nishioka SA, Santos TL, Santos RP, Santos PS, Rocha A. Hantavirus pulmonary syndrome in Brazil: clinical aspects of three new cases. Rev Inst Med Trop São Paulo. 2000;42:41-6.

7. Pinto Junior VL, Hamidad AM, Albuquerque Filho DO, Santos VM. Twenty years of hantavirus pulmonary syndrome in Brazil: a review of epidemiological and clinical aspects. J Infect Dev Ctries. 2014;8:137-42.

8. Brasil. Ministério da Saúde. Secretaria de Vigilância em Saúde. Departamento de Vigilância Epidemiológica. Manual de vigilância, prevenção e controle das hantaviroses. Brasília: Ministério da Saúde; 2013.

9. Brasil. Ministério da Saúde. Casos confirmados de Hantavirose: Brasil, Grandes Regiões e Unidades Federadas, 19932018. [cited 2019 Sep 10]. Available from: https:// portalarquivos2.saude.gov.br/images/pdf/2019/janeiro/25/ CONF-HANTA-25-01-2019.pdf

10. São Paulo. Secretaria de Saúde. Divisão de Zoonoses. Distribuição do número de casos e óbitos de Hantavírus: Estado de São Paulo - 1993 a 2018, jan a dezembro. [cited 2019 Sep 10]. Available from: http://www.saude.sp.gov.br/resources/cvecentro-de-vigilancia-epidemiologica/areas-de-vigilancia/ 
doencas-de-transmissao-por-vetores-e-zoonoses/dados/ hantavirose/hanta_cobito.pdf

11. Figueiredo LT, Campos GM, Rodrigues FB. Síndrome pulmonar e cardiovascular por hantavírus: aspectos epidemiológicos, clínicos, do diagnóstico laboratorial e do tratamento. Rev Soc Bras Med Trop. 2001;34:13-23.

12. Simpson SQ, Spikes L, Patel S, Faruqi I. Hantavirus pulmonary syndrome. Infect Dis Clin North Am. 2010;24:159-73.

13. Safronetz D, Prescott J, Feldmann F, Haddock E, Rosenke R, Okumura A, et al. Pathophysiology of hantavirus pulmonary syndrome in rhesus macaques. Proc Natl Acad Sci U S A. 2014;111:7114-9.

14. Guzmán GP, Tapia EO, Villaseca HM, Araya OJ, Antonio PL, Lee OB, et al. Hallazgos morfológicos en casos fatales de síndrome cardiopulmonar por hantavirus: estudio de 7 autopsias. Rev Chilena Infectol. 2010;27:398-405.

15. Silva-Vergara ML, Costa Júnior JC, Barata CH, Curi VG, Tiveron Júnior CG, Teixeira AC. Hantavirus pulmonary syndrome in Uberaba, Minas Gerais, Brazil. Mem Inst Oswaldo Cruz. 2002;97:783-7.
16. Limongi JE, Oliveira RC, Guterres A, Costa Neto SF, Fernandes J, Vicente LH, et al. Hantavirus pulmonary syndrome and rodent reservoirs in the savanna-like biome of Brazil's southeastern region. Epidemiol Infect. 2016;144:1107-16.

17. Araujo J, Duré AI, Negrão R, Ometto T, Thomazelli LM, Durigon EL. Co-circulation in a single biome of the Juquitiba and Araraquara hantavirus detected in human sera in a sub-tropical region of Brazil. J Med Virol. 2015;87:725-32.

18. Bi Z, Formenty PB, Roth CE. Hantavirus infection: a global review and global update. J Infect Dev Ctries. 2008;2:3-23.

19. Saggioro FP, Rossi MA, Duarte MI, Martin CC, Alves VA, Moreli ML, et al. Hantavirus infection induces a typical myocarditis that may be responsible for myocardial depression and shock in hantavirus pulmonary syndrome. J Infect Dis. 2007;195:1541-9.

20. Ermonval M, Baychelier F, Tordo N. What do we know about how hantaviruses interact with their different hosts? Viruses. 2016;8:223. 